\title{
Embolizing pulmonary aspergillosis, mycobacterial \& aspergillous splenic abscess and cytomegalovirus co-infection following steroid induced immunosuppression: a case report
}

\author{
Harsha Anuruddhika Dissanayake ${ }^{1 *}$ (D) Praveen Nilendra Weeratunga ${ }^{1}$, Panduka Karunanayake ${ }^{2}$, \\ Rushika D. Lanerolle ${ }^{2}$, M. V. Chandu de Silva ${ }^{3}$ and Saroj Jayasinghe ${ }^{2}$
}

\begin{abstract}
Background: Aspergillosis is a serious infection particularly affecting the immunodeficient host. Its co-infection with tuberculosis and cytomegalovirus has not been reported before. Embolic events are well recognized with aspergillous endocarditis and aortitis. Splenic abscess is a rare serious complication of disseminated aspergillosis and is difficult to treat. We report the first case of multiple embolic events and splenic abscess in a patient with pulmonary aspergillosis and cytomegaloviral and tuberculous co-infection, without endocarditis or aortitis.

Case presentation: Thirty-year-old male presented with fever and non-productive cough while on glucocorticoids for glomerulonephritis. He was found to have pulmonary aspergillosis and subsequently developed bilateral lower limb and cerebral fungal emboli and fungal abscess in the spleen. He had IgM and B cell deficiency and cytomegalovirus (CMV) and tuberculous co-infections. He recovered after prolonged course of antimicrobials, splenectomy and cessation of glucocorticoid therapy which also lead to the resolution of immune deficiencies.

Conclusion: This report illustrates rare combination of B and T cell suppressive effects of glucocorticoids leading to co-infections with CMV, Mycobacterium tuberculosis and Aspergillus and systemic fungal embolization from pulmonary aspergillosis.
\end{abstract}

Keywords: Aspergillosis, Fungal embolism, Acquired immune deficiency, Glucocorticoids, Splenic abscess

\section{Background}

Aspergillus species cause serious infections in immunocompromised host. Common sites of infection are lungs and sinuses while central nervous system, cardiac valves and aorta are affected less frequently. Aspergillus species account for $28 \%$ of fungal endocarditis and are recognized to form large vegetations [1]. Embolizations to cerebral, lower limb, mesenteric and renal vasculature have been reported. Aspergillus aortitis is also known to cause distant embolic phenomena [2].

\footnotetext{
* Correspondence: dissanayakeha@gmail.com

${ }^{1}$ University Medical Unit, National Hospital of Sri Lanka, Colombo, Sri Lanka Full list of author information is available at the end of the article
}

We report a patient with acquired immunodeficiency secondary to glucocorticoid use that developed simultaneous cytomegaloviral, tuberculous and pulmonary Aspergillus infections, complicated with multiple embolizations to cerebral and lower limb arteries and splenic abscess, without evidence of endocarditis or aortitis. Possible mechanisms of disease are discussed.

\section{Case presentation}

A thirty-year-old male presented with fever and non-productive cough for 2 weeks with exertional dyspnoea. He had hypertension and renal impairment due to mesangioproliferative glomerulonephritis, diagnosed 3 months prior to current presentation, and was on

(c) The Author(s). 2018 Open Access This article is distributed under the terms of the Creative Commons Attribution 4.0 International License (http://creativecommons.org/licenses/by/4.0/), which permits unrestricted use, distribution, and reproduction in any medium, provided you give appropriate credit to the original author(s) and the source, provide a link to the Creative Commons license, and indicate if changes were made. The Creative Commons Public Domain Dedication waiver (http://creativecommons.org/publicdomain/zero/1.0/) applies to the data made available in this article, unless otherwise stated. 
bisoprolol, prazosin and prednisolone $(0.5 \mathrm{mg} / \mathrm{kg} /$ day $)$. Renal biopsy had not shown evidence of vasculitis.

On examination he was emaciated (BMI $18 \mathrm{~kg} / \mathrm{m}^{2}$ ), febrile $\left(38.2{ }^{\circ} \mathrm{C}\right)$, and had coarse crackles over right upper lung. Other system examinations were unremarkable.

The patient had a pancytopaenia with neutropaenia (neutrophil count $780 / \mathrm{mm}^{3}$ ) and dysplastic hypoproliferative bone marrow. Peripheral blood detected cytomegalovirus $(29,000$ copies per microliter by PCR) and anti-CMV IgM was positive. After 21 days of ganciclovir (100 mg daily IV), CMV viral load became undetectable and pancytopaenia was corrected.

Contrast enhanced CT-chest showed right upper lobe consolidation with cavities (Fig. 1). Sputum smear for acid fast bacilli, culture and PCR for mycobacteria (Xpert MTb/RIF) were negative. However, tuberculosis PCR (IS6110 method) performed on his bone marrow aspirate was positive. Therefore, anti tuberculous therapy with isoniazid, rifampicin, ethambutol and pyrazinamide were commenced for disseminated tuberculosis. But, the response was poor.. Aspergillus fumigatus was detected on bronchoalveolar lavage wet smear and culture. Both lavage and serum were positive for galactomannan antigen. Therefore voriconazole $500 \mathrm{mg}$ twice daily (oral) was commenced.

On sixth week of voriconazole, the patient developed acute bilateral lower limb ischaemia. Two emboli occluding bilateral popliteal arteries were extracted during emergency embolectomy (Fig. 2). Histology of emboli showed fungal filaments and culture isolated Aspergillus fumigatus. Trans-esophageal echocardiogram and magnetic resonance imaging (MRI) of the aorta were normal. However, MRI abdomen incidentally detected a large splenic abscess (Fig. 3a).

Despite treatment with voriconazole for further 2 weeks, the splenic abscess enlarged and treatment was switched to liposomal amphotericin $3 \mathrm{mg} / \mathrm{kg} /$ day intravenously. Four weeks later he developed acute left upper

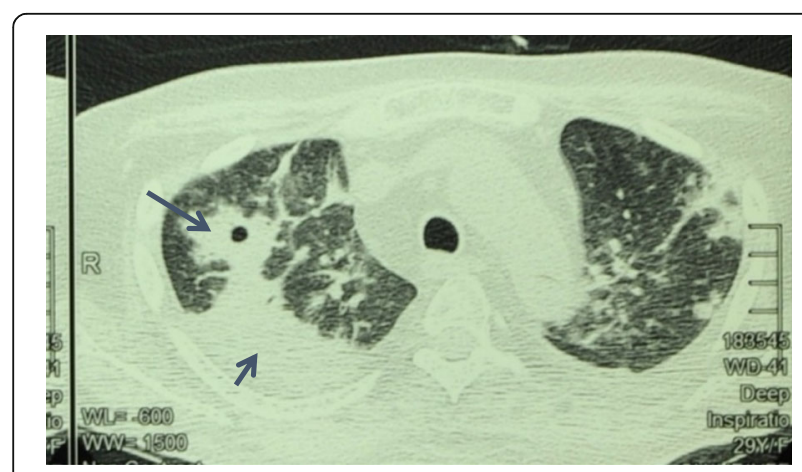

Fig. 1 Contrast $\subset T$ chest showing consolidation nodules and cavitation of upper lobe of the right lung (long arrow: cavity, short arrow - consolidation)

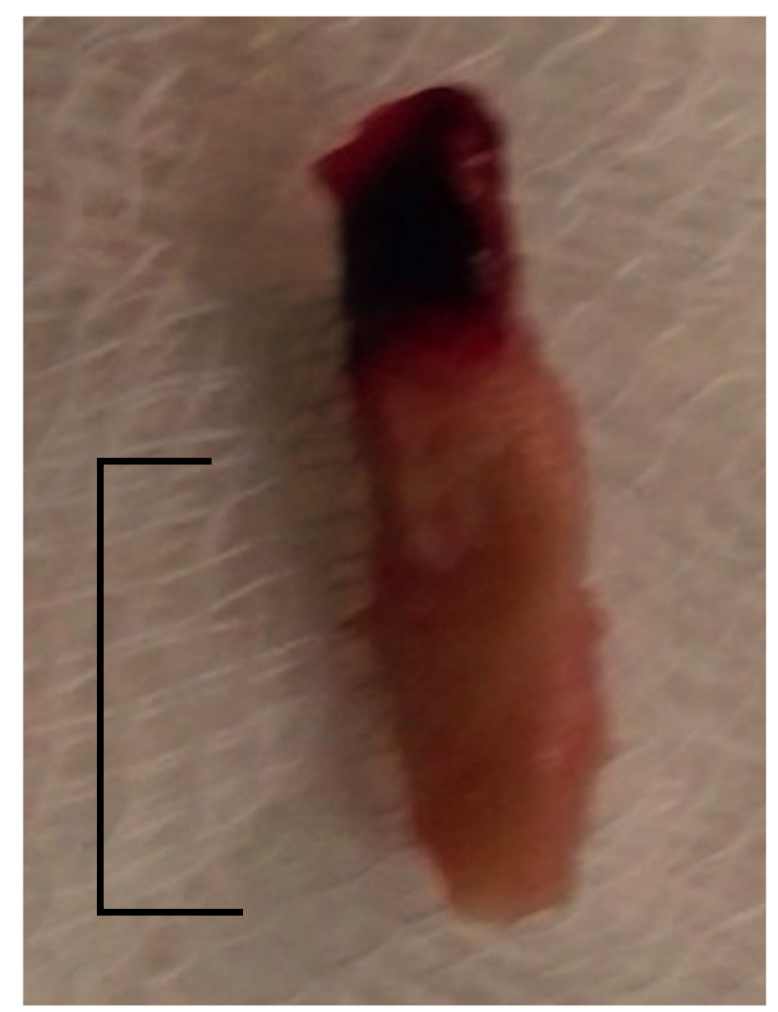

\section{* scale $1 \mathrm{~cm}$}

Fig. 2 Embolus extracted from the right popliteal artery (scale $10 \mathrm{~mm}$ )

motor neuron type facial nerve palsy. MRI brain showed multiple small focal lesions in capsular and cortical regions suggestive of fungal embolism (Fig. 4). The neurological deficit completely resolved within a week.

Percutaneous aspiration under ultrasound guidance and 6 weeks of amphotericin failed to clear the splenic abscess. Therefore the patient underwent elective splenectomy. Histology of the splenic tissue showed fungal filaments within the abscess as well as caseating granulomas suggestive of tuberculosis of spleen (Fig. 3b).

Post-operative period was complicated with left Lower lobe pneumonia and parapneumonic effusion, from which he recovered with antibiotics and supportive measures. Subsequently, fever resolved and clinical status improved (see Additional file 1 for the timeline of disease evolution).

Due to the unusual constellation of infections (CMV, tuberculosis and aspergillosis) the patient was screened for an immune deficiency state which revealed B cell, IgM and IgA deficiencies and impaired T cell proliferation with concanavalin A (Table 1). Steroids were tapered and stopped 3 months after the current presentation. Six months later above immune defects returned to normal. Autoantibody profile (ANA, ANCA, rheumatoid factor and extracatable nuclear antibody profile) and HIV screening were negative on two occasions 


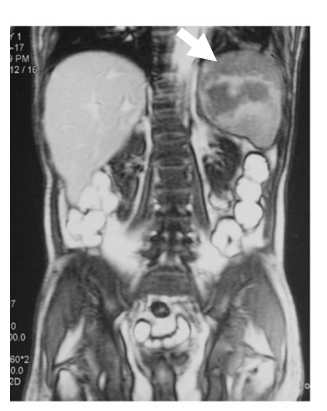

(a)

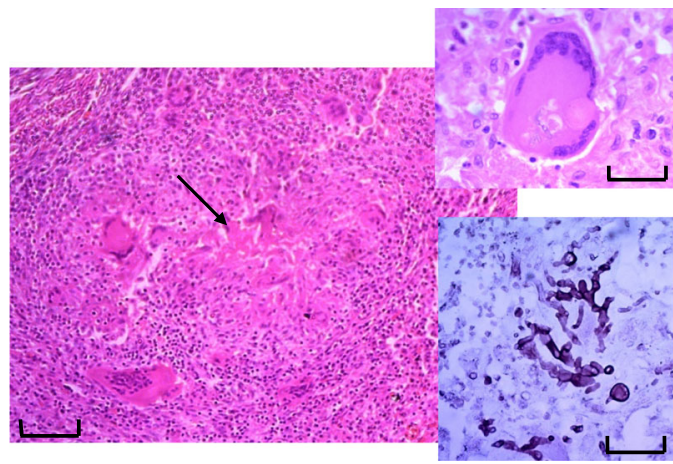

(b)

Fig. 3 a Splenic abscess on MRI abdomen (white arrow). b Histology of splenic tissue demonstrating caseating granuloma (black arrow; in low power, scale $100 \mu \mathrm{m}$ ). Upper inlet shows granuloma with a multinucleated giant cell and lower inlet shows fungal filaments within granuloma demonstrated with Grocott stain in high power (scale $25 \mu \mathrm{m}$ )

4 months apart. Repeated imaging, bone marrow trephine and tumor screening with tumor markers did not identify any neoplasms.

\section{Discussion}

Disseminated invasive aspergillosis is a serious fungal infection particularly affecting the immune compromised individuals. Risk factors are immune deficiency either primary, or secondary to cytotoxic drugs, steroids, prolonged antibiotic use and haematological or solid organ malignancies. Structural lung disease and valve disease predispose to pulmonary aspergillosis and endocarditis respectively. This patient was on steroids, had myelodysplasia and severe B cell deficiency with IgM deficiency and T cell dysfunction with transient neutropaenia (that rapidly recovered with treatment of CMV). Immune response against Aspergillus is predominantly innate system dependent and neutrophil mediated [3]. Nevertheless, disseminated aspergillosis in a patient with selective IgM deficiency has been described before [4].

Multiple embolic events are known to occur in patients with Aspergillus endocarditis [1] and aortitis [2, 5, 6]. However, repeated trans-esophageal echocardiograms and magnetic resonance aortogram did not show valve defects, vegetations, aortitis or aneurysms. Therefore, we postulate that pulmonary aspergillosis was the primary focus from where fungal particles embolized through pulmonary veins and left heart into systemic circulation.

Splenic abscess was an incidental finding in our patient who did not have symptoms attributable to it. We think this was due to blood borne dissemination of $M$. tuberculosis bacilli, which was subsequently invaded by Aspergillus during a fungaemic phase. Caseating granuloma characteristic of tuberculosis was observed in splenic tissue (Fig. 3). Mycobacteria were not visualized microscopically or cultured from the abscess fluid, probably because 4 months of anti-tuberculosis therapy was completed by the time of splenectomy. Furthermore, $A s$ pergillus has never been reported to cause caseating granulomas. Larger fungal embolization in to spleen with secondary tuberculous infection seems less likely due to the tortuous course of splenic artery and acute angle at the coeliac trunk origin. Furthermore, the patient never developed acute left hypochondrial pain suggestive of embolic splenic infarct. Fungal filaments were observed within the caseating granulomas in splenic

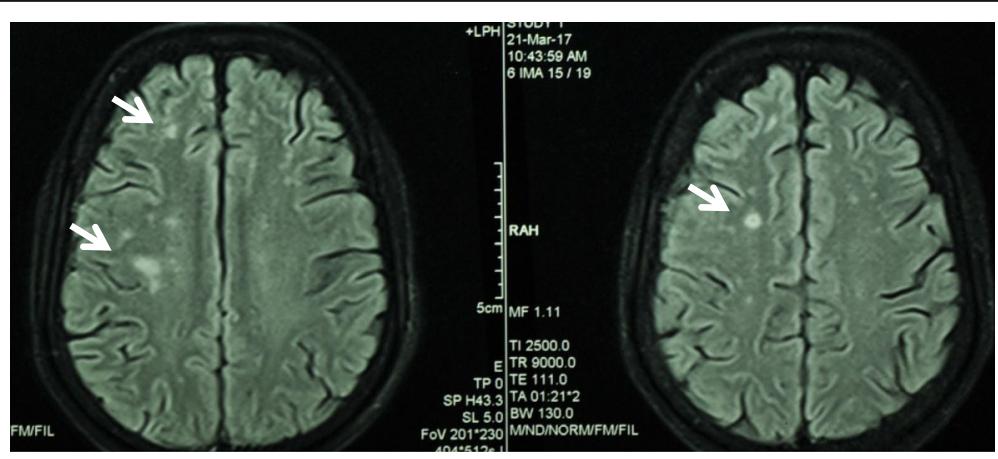

Fig. $4 \mathrm{MRI}$ brain showing multiple cortical infarcts (white arrows) 
Table 1 Summary of immune function assessment

\begin{tabular}{|c|c|c|c|}
\hline & 24 December 2016 (while on tapering steroids) & 1 July2017 (6 months after steroid cessation) & Reference range \\
\hline Total white cell count (per $\mathrm{mm}^{3}$ ) & 5600 & 6700 & $4000-11,000$ \\
\hline CD3 count (per mm³) & 1866 & 1862 & $700-2100$ \\
\hline CD4 count (per mm³) & 580 & 760 & $300-1400$ \\
\hline CD8 count (per $\mathrm{mm}^{3}$ ) & 1306 & 1102 & 200-900 \\
\hline CD19 count (per $\mathrm{mm}^{3}$ ) & 23 & 388 & $100-500$ \\
\hline IgM level (mg/dL) & 14 & 65 & $47-147$ \\
\hline IgG level (mg/dL) & 843 & 2283 & 569-1919 \\
\hline IgA level (mg/dL) & 52 & 352 & $61-330$ \\
\hline Nitroblue tetrazolium assay & Normal & - & - \\
\hline T cell proliferation assay & Mild impairment & Normal & - \\
\hline
\end{tabular}

tissue, which suggests co-infection of an existing caseating abscess. Although Aspergillus was never isolated from peripheral blood cultures, it does not rule out a fungaemia. Negative peripheral blood fungal cultures are not uncommon with disseminated fungal infection [7].

Disseminated tuberculosis would have formed splenic granulomas which were co-infected with Aspergillus during fungaemic phase. Complex alterations in immune system caused by glucocorticoids would have facilitated this unusual co-infection. Infections themselves can alter the immune response (e.g.: neutropaenia and $\mathrm{T}$ cell dysfunction due to CMV). This would also have contributed to the unusual co-infection.

Management of splenic abscess was challenging. Initial treatment with anti-fungals and percutaneous aspiration failed to clear the abscess necessitating splenectomy, despite the risks of surgical complications and further compromise of immunity. Voriconazole-rifampicin interaction and its poor penetration into abscess may have contributed to antifungal failure. Therapeutic drug monitoring (target trough level $>1 \mathrm{mg} / \mathrm{L}$ ) is recommended when treating patients with voriconazole, especially when interacting drugs are co-prescribed [8]. Unfortunately, this facility was not available for us.

Assessment of the patient's immune system revealed severe IgM deficiency, mild IgA deficiency, severe B cell deficiency and impaired $\mathrm{T}$ cell functions but normal $\mathrm{T}$ cell counts, neutrophil counts and functions on nitro-blue tetrazolium assay. Although glucocorticoids may give rise to some of the above abnormalities, IgM deficiency is not a recognized effect of glucocorticoid therapy $[9,10]$. Nephrotic syndrome causes immunoglobulin deficiency. However this patient's glomerular disease with subnephrotic proteinuria cannot explain B cell deficiency and predominant IgM rather than IgG deficiency.

Multiple severe unusual infections in this patient developed after commencement of glucocorticoids. Immune deficiencies completely reversed after its discontinuation.
The patient had no features of immune defects prior to this illness. Therefore glucocorticoids are the most likely cause for the immune dysfunction. Impact of glucocorticoids on immune system are predominantly on $\mathrm{T}$ cells [11]. T cell dysfunction is a risk factor for CMV infection and was the likely culprit in our patient. Although steroids slightly reduce $B$ cell numbers, immunoglobulin production is not affected in short term $[9,12]$. B cells require assistance of $\mathrm{T}$ cells for normal immunoglobulin production. After years of glucocorticoid therapy, suppression of $\mathrm{T}$ cells can therefore reduce immunoglobulin synthesis. However, this occurs only with long term glucocorticoids therapy and IgA and IgG are the predominantly affected subtypes [13]. Therefore, observations in our patient are unusual, as the B cell depletion was marked, and it developed within few months of steroid therapy and, IgM was predominantly affected subtype. Glucocorticoids induced severe B cell depletion in our patient would have lead to IgM deficiency. No other factor could explain the transient immune dysfunction in the patient.

CMV infection itself is known to suppress $\mathrm{T}$ cell mediated immunity by TNF-alfa mediated expression of arachidonic acid and prostaglandin-E2 from infected monocytes [14]. This extreme state of $\mathrm{T}$ cell dysfunction with glucocorticoids and CMV infection would have predisposed him to develop disseminated tuberculosis. However, CMV infection activates plasmacytoid dendritic cells which increase proliferation and activation of B cells [15]. Therefore, CMV infection does not explain our patient's severe B cell deficiency.

\section{Conclusion}

This case highlights several features of interest. First, to the best of our knowledge, this is the first case of concomitant CMV, tuberculous and aspergillous infection in a transient state of immunosuppression. Second, our patient developed multiple fungal emboli from a pulmonary focus of aspergillosis, a phenomenon not described before. Third, the patient had a severe B cell and IgM 
deficiency, which reversed after discontinuation of glucocorticoids. This effect has not been described before and therefore we highlight the need for further studies on effects of glucocorticoids on human immune system. Finally, this case illustrates the importance of judicious use of glucocorticoids being aware of their wide range of effect on human immune system.

\section{Additional file}

Additional file 1: Timeline. Graphical representation of temporal evolution of the disease. (DOCX $38 \mathrm{~kb}$ )

\section{Abbreviations}

ANA: Antinuclear antibodies; ANCA: Anti neutrophil cytoplasmic antibodies: BMI: Body mass index; CMV: Cytomegalovirus; CT: Computed tomography; dsDNA: double stranded deoxyribonucleic acid (antibodies); HIV: Human immunodeficiency virus; MRI: Magnetic resonance imaging; PCR: Polymerase chain reaction

\section{Acknowledgements}

Authors would like to thank Dr. Ruwan Fonseka, Consultant Vascular Surgeon, National Hospital of Sri Lanka (NHSL) and Dr. Donald Ruban, Senior Registrar in vascular surgery, NHSL for the contribution of the images of embolectomy specimens, Dr. Suneetha Weerakoon, Consultant Radiologist, NHSL for the contribution of MRI images, Dr. Rajiva de Silva, Consultant Immunologist, Medical Research Institute, Colombo for the contribution with immune function assessments and Dr. S Sivaganesh, Consultant Surgeon, NHSL for provision of surgical specimens, Dr. Aflah Sadikeen, Consultant Respiratory Physician, NHSL and all staff members of University Medical Unit, NHSL and departments of Clinical Medicine and Pathology, University of Colombo for their assistance in patient care. Patient and family are sincerely acknowledged for their patience and co-operation throughout the period of illness.

\section{Availability of data and materials}

Not applicable. All data used for the case report were from patients past medical records and investigation findings during hospital stay and carry the patient's identity. Authors do not wish to share that information in public to ensure confidentiality and since relevant information are noted in this report.

\section{Authors' contributions}

HAD and PNW collected data, reviewed literature and compiled the manuscript. PK, RDL, and SJ critically reviewed the paper. MVCS provided histology images and contributed to the discussion of histopathology. All were involved in patient care. All authors reviewed the final manuscript and approved prior to submission.

\section{Ethics approval and consent to participate}

Not applicable.

\section{Consent for publication}

Patient gave written informed consent to publish the clinical details and images without breaching confidentiality.

\section{Competing interests}

The authors declare that they have no competing interests.

\section{Publisher's Note}

Springer Nature remains neutral with regard to jurisdictional claims in published maps and institutional affiliations.

\section{Author details}

'University Medical Unit, National Hospital of Sri Lanka, Colombo, Sri Lanka. ${ }^{2}$ Department of Clinical Medicine, Faculty of Medicine, University of Colombo, Colombo, Sri Lanka. ${ }^{3}$ Department of Pathology, Faculty of Medicine, Colombo, Sri Lanka.
Received: 22 January 2018 Accepted: 1 August 2018

Published online: 06 August 2018

\section{References}

1. Kalokhe AS, et al. Aspergillus endocarditis: a review of the literature. Int J Infect Dis. 2010;14(12):e1040-7.

2. Abenza-Abildua MJ, et al. Stroke due to septic embolism resulting from Aspergillus aortitis in an immunocompetent patient. J Neurol Sci. 2009; 284(1-2):209-10.

3. Hohl TM. Immune responses to invasive aspergillosis: new understanding and therapeutic opportunities. Curr Opin Infect Dis. 2017;30(4):364-71.

4. Hong R, Gupta S. Selective immunoglobulin M deficiency in an adult with Streptococcus pneumoniae sepsis and invasive aspergillosis. J Investig Allergol Clin Immunol. 2008;18(3):214-8.

5. Jamieson RW, et al. Acute aortic occlusion with sudden paraplegia secondary to Aspergillus Niger embolism from Aspergillus Niger aortitis. J Vasc Surg. 2011;54(5):1472-4.

6. Noordally $\mathrm{SO}$, et al. Late onset of Aspergillus aortitis presenting as femoral artery embolism following coronary artery bypass graft surgery. Acta Med (Hradec Kralove). 2012;54(4):175-6.

7. Barton RC. Laboratory diagnosis of invasive aspergillosis: from diagnosis to prediction of outcome. Scientifica (Cairo). 2013:2013:459405.

8. Ashbee HR, et al. Therapeutic drug monitoring (TDM) of antifungal agents: guidelines from the British Society for Medical Mycology. J Antimicrob Chemother. 2014;69(5):1162-76.

9. Settipane GA, Pudupakkam RK, McGowan JH. Corticosteroid effect on immunoglobulins. J Allergy Clin Immunol. 1978;62(3):162-6.

10. Wirsum $C$, et al. Secondary antibody deficiency in glucocorticoid therapy clearly differs from primary antibody deficiency. J Clin Immunol. 2016;36(4):406-12.

11. Slade JD, Hepburn B. Prednisone-induced alterations of circulating human lymphocyte subsets. J Lab Clin Med. 1983;101(3):479-87.

12. Coutinho AE, Chapman KE. The anti-inflammatory and immunosuppressive effects of glucocorticoids, recent developments and mechanistic insights. Mol Cell Endocrinol. 2010;335(1):2-13.

13. Fedor ME, Rubinstein A. Effects of long-term low-dose corticosteroid therapy on humoral immunity. Ann Allergy Asthma Immunol. 2006; 97(1):113-6

14. Nokta MA, et al. Human cytomegalovirus-induced immunosuppression. Relationship to tumor necrosis factor-dependent release of arachidonic acid and prostaglandin E2 in human monocytes. J Clin Invest. 1996;97(11):2635-41.

15. Varani $S$, et al. Human cytomegalovirus differentially controls B cell and T cell responses through effects on plasmacytoid dendritic cells. J Immunol. 2007:179(11):7767-76.

\section{Ready to submit your research? Choose BMC and benefit from:}

- fast, convenient online submission

- thorough peer review by experienced researchers in your field

- rapid publication on acceptance

- support for research data, including large and complex data types

- gold Open Access which fosters wider collaboration and increased citations

- maximum visibility for your research: over $100 \mathrm{M}$ website views per year

At $\mathrm{BMC}$, research is always in progress.

Learn more biomedcentral.com/submissions 